\title{
Solitary Peutz-Jeghers-type hamartomatous polyp as a cause of recurrent acute pancreatitis
}

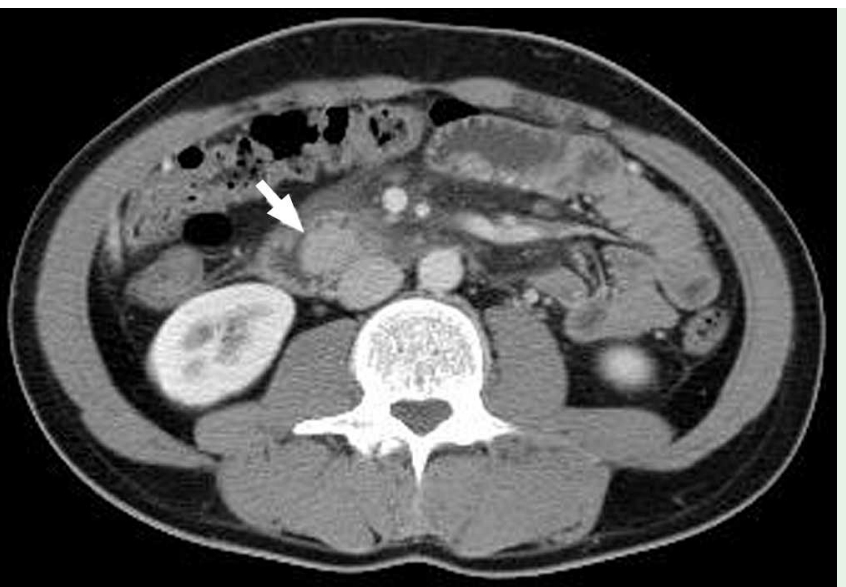

Fig. 1 Axial contrastenhanced CT scan showing a homogeneous, well-circumscribed mass (arrow) with a diameter of $2.5 \mathrm{~cm}$ in the second part of the duodenum and loss of homogeneity of the peripancreatic mesenteric fat planes.

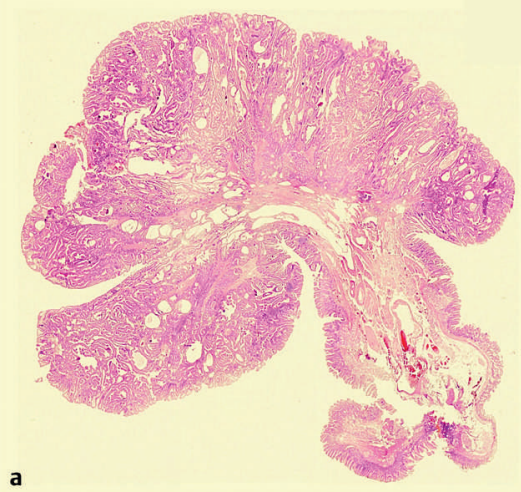

Fig. 3 Low-power view of the resected specimen showing a cauliflower-like polypoid lesion with dilated vascular channels traversing its stalk. b Several cystic glands as well as smooth muscle bundles originating from the muscularis mucosa and extending towards the subepithelial connective tissue can also be seen. The epithelium was hyperplastic in nature but there was no dysplasia.

A 28-year-old man was referred to us with a diagnosis of acute pancreatitis. The patient had experienced abdominal pain, nausea, and vomiting. In the 2 months prior to admission, he had been admitted and treated for acute pancreatitis twice in another hospital. He had no history of alcohol intake or habitual drug use. The physical examination was unremarkable except for epigastric tenderness, but his amylase level was markedly raised (2461 $\mathrm{IU} / \mathrm{L}$ [normal range <480 IU/L]). Abdominal ultrasonography and computed tomography (CT) revealed mild edematous acute pancreatitis without gallstones. The CT scan also showed a large $(2.5 \mathrm{~cm} \times 1.5 \mathrm{~cm}), \quad$ well-circumscribed mass in the second part of the duodenum ( $\bullet$ Fig. 1). Magnetic resonance cholangio- pancreatography demonstrated normal common bile duct and pancreatic duct. Endoscopic retrograde cholangiopancreatography (ERCP) was carried out, and a large, pedunculated polyp, originating from the second part of the duodenum and extending further down into the third part over the ampulla of Vater, was visualized during the procedure ( $\bullet$ Fig. 2 and Video 1). Polypectomy was done using a standard snare, and minor bleeding following the procedure was controlled by injecting epinephrine. Histologically, the polyp consisted of branching bundles of muscle fibers derived from the muscularis mucosa and covered by hyperplastic duodenal mucosa, compatible with a Peutz-Jeghers-type hamartomatous polyp ( $\odot$ Fig. 3 ). The patient had

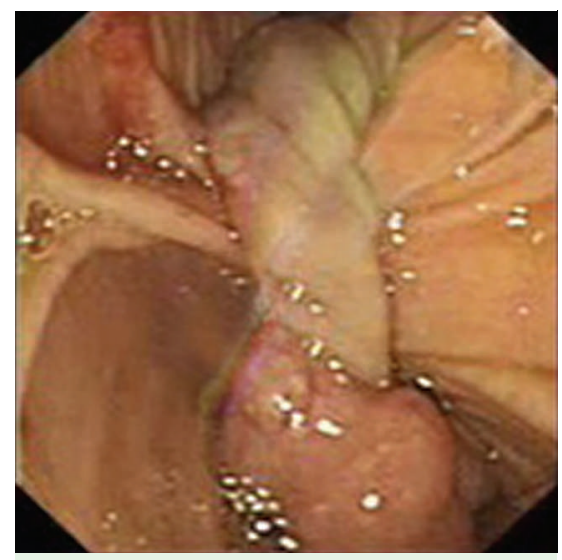

Fig. 2 Endoscopic retrograde cholangiopancreatography (ERCP) revealing a large, pedunculated polyp with a thick stalk originating in the second part of the duodenum and extending into the third part of the duodenum.

no mucocutaneous pigmentation suggestive of Peutz-Jeghers syndrome and the family history was negative. A total ileocolonoscopy was done, but the findings were normal. The patient has remained well at 9 months after discharge without further recurrence of pancreatitis. The earlier recurrence of acute pancreatitis was attributed to intermittent obstruction of the papilla of Vater by the hamartomatous polyp.

To date, only a few well-documented cases of a solitary Peutz-Jeghers-type hamartomatous polyp of the duodenum without other features of Peutz-Jeghers syndrome have been reported. This type of hamartomatous polyp is now considered as a separate disease entity from Peutz-Jeghers syndrome [1,2]. To our knowledge, this report represents the first case of recurrent acute pancreatitis caused by a solitary Peutz-Jeghers-type hamartomatous polyp in the duodenum.

Endoscopy_UCTN_Code_CCL_1AB_2AZ_3AB

Video 1

Endoscopic polypectomy of a solitary PeutzJeghers-type hamartomatous polyp. 
M. Kantarcioglu ${ }^{1}$, G. Kilciler ${ }^{1}$, I. Turan ${ }^{1}$,

C. N. Ercin ${ }^{1}$, Y. Karslioglu², I. Guvenc ${ }^{3}$,

Z. Polat ${ }^{1}$, S. Bagci ${ }^{1}$

1 Department of Gastroenterology, Gulhane Military Medical Academy, School of Medicine, Ankara, Turkey

2 Department of Pathology, Gulhane Military Medical Academy, School of Medicine, Ankara, Turkey

3 Department of Radiology, Gulhane Military Medical Academy, School of Medicine, Ankara, Turkey

\section{References}

1 Acea Nebril B, Taboada Filgueira L, Parajo Calva $A$ et al. Solitary hamartomatous duodenal polyp; a different entity: report of a case and review of the literature. Surg Today 1993; 23: $1074-1077$

2 Itaba S, Namoto M, Somada Set al. Two cases of solitary Peutz-Jeghers-type hamartoma of the duodenum. Endoscopy 2006; 38 (Suppl 2): E32-E33
Bibliography

DOI 10.1055/s-0029-1214705

Endoscopy 2009; 41: E117-E118

(c) Georg Thieme Verlag KG Stuttgart · New York . ISSN 0013-726X

Corresponding author

\section{Kantarcioglu, MD}

GATA Gastroenteroloji Bilim Dali

Etlik

06010 Ankara

Turkey

Fax: +90-312-3042010

kantarci@hotmail.com 